\title{
Inflation and Food Security in Pakistan: Impact and Coping Strategies*
}

\author{
Haris Gazdar and Hussain Bux Mallah
}

\begin{abstract}
Food security will remain an important component of any strategy for nutritional improvement in Pakistan. The country experienced acute price spikes and shortages during 2007 and 2008, corresponding with food price inflation and volatility in global markets. This led to the clearer articulation of a food security approach based on a closer alignment with world prices and the establishment of a cash transfer programme to compensate poor households. This article presents the results of a qualitative study of food security among rural and urban households in selected regions to better understand the perceptions, behaviour, processes and coping strategies of the poor with regard to food security in general, and price shocks in particular. The study offers insights into gaps in existing policy approaches to food security and potential areas of pro-nutrition policy change.
\end{abstract}

\section{Introduction}

Although nutrition has been framed as a predominantly health sector concern in Pakistan, food security, defined as the condition 'when all people, at all times, have physical and economic access to sufficient, safe, and nutritious food, and to meet their dietary needs and food preference for an active and healthy life' (FAO 1996), will remain an important component of any overarching nutrition policy. Like most countries with relatively open economies, Pakistan experienced food security challenges due to food price inflation and volatility in 2007 and 2008.

The broad trends in prices were in line with conditions in global markets and other comparable countries. National policies, however, were thought to have contributed to specific price spikes and temporary but acute shortages in local markets, leading to heightened concerns about hunger and malnutrition.

A review of existing policies and a clearer articulation of a food security strategy ensued (see Balagamwala and Gazdar, this IDS Bulletin). This strategy consisted of two main components: (a) ensuring local availability and market functioning for the main staple, wheat, by closing the gap between procurement and expected global prices; and (b) compensating poor and vulnerable households through direct cash transfers. The strategy has been successful in achieving some of its objectives. Its first part, or the reform of wheat procurement prices, is accredited with preventing price spikes and shortages and boosting crop production, while the second part is associated with significant progress towards the establishment of a largescale social protection system (Gazdar 2011).

The immediate objectives of the food security strategy, which have been achieved with some degree of success, do not encompass the range of issues related to the broader agenda of food security. Prevention of shortages and the smooth functioning of markets pre-empt crises but do not, in themselves, ensure access to sufficient, safe and nutritious food for all. Food security analyses in Pakistan have tended to focus either on aggregate food availability at the national or district levels (e.g. SDPI, WFP and SDC 2009; SDPI and WFP 2004), or on actual food (and calorie) consumption at the household level using the recall method (Friedman et al. 2011). More detailed and insightful but dated studies on the dynamics of food acquisition and consumption based on panel household surveys suggested that 


\begin{tabular}{|c|c|c|c|c|}
\hline Site & District & Province/region & Characteristics & $\begin{array}{l}\text { Household in-depth } \\
\text { interviews }\end{array}$ \\
\hline Killa Darawar & Bahawalpur & Punjab, southern & Semi-arid & 3 \\
\hline Kandair & Jamshoro & Sindh, central & Semi-arid & 3 \\
\hline Chhoti Vasti & Multan & Punjab, southern & Irrigated & 3 \\
\hline Rawal Pahor & Hyderabad & Sindh, central & Irrigated & 4 \\
\hline Ajwain Sharif & Multan & Punjab, southern & Peri-urban & 4 \\
\hline Ferozianwala & Lahore & Punjab, central & Urban & 3 \\
\hline Jewan Hana & Lahore & Punjab, central & Urban & 3 \\
\hline Total & & & & 23 \\
\hline
\end{tabular}

variations within households and over time (both across and within seasons) might be important correlates of nutritional outcomes (Alderman and Garcia 1992).

Major gaps remain, however, in our knowledge of the perceptions, behaviour and experiences of poor and vulnerable households in rural and urban areas with respect to food security, acquisition, consumption and response to adverse shocks. This article is an attempt to plug some of these knowledge gaps using the findings of a qualitative survey on the impact of food price and availability shocks on purposively selected poor and vulnerable households in rural and urban communities across two provinces. The qualitative research aimed to address questions whose answers have been important sources of insight into processes behind nutritional outcomes in neighbouring countries (e.g. Coates et al. 2003 in Bangladesh; Chung et al. 1997 in India):

- How do poor and marginalised individuals and families perceive food security and insecurity?

- What are the main strategies for such individuals and families for the acquisition of food that they consider to be essential for their food security?

- What are the salient shocks that affect their food economy and security?

- In what way do price shocks figure as significant factors in the food economy of these groups?

- How have the poor and marginalised individuals and families coped with the adverse shocks that they faced?
What are the main sources of external support in the communities under study, and how do these affect the food insecurity of poor individuals and families?

\section{Methodology}

\subsection{Instruments}

Fieldwork was conducted in 2010 - some two years after the peak of the food price crisis - in a number of rural and urban sites. Qualitative research instruments included community profiling, in-depth household interviews, structured and unstructured focus group discussions and food price data from local grocery shops. Community profiling was carried out in each site through instruments such as physical and social mapping to locate diverse communities and infrastructure.

Wealth rankings were carried out to classify households into three broad categories: poor, medium and rich. As in the case of most qualitative surveys, this classification was a relative one within a fieldwork site, and did not represent cross-site standardisation. The classification was important, however, in order to ensure that within the fieldwork sites we were able to identify poor and non-poor households. Structured and unstructured focus group discussions were conducted to understand communities' perceptions and definitions regarding food security and insecurity. For in-depth household interactions we aimed to select at least two poor and one non-poor household in each of the sites. The ratio of female and male respondents for in-depth household interactions was 2:1 in each site. 


\subsection{Site selection}

Survey sites were selected purposively to represent diverse social, economic, agro-climatic and infrastructure conditions in rural and urban areas in the two more populous provinces (Punjab and Sindh). Two of the rural sites were purposively selected in irrigated regions while the other two were in semi-arid regions with relatively low levels of agricultural productivity. In addition, two urban and one peri-urban site were selected in Punjab (Table 1). Community profiling and focus group discussions were conducted in each of the sites, and a total of 23 in-depth household interactions, 15 with women and eight with men, were conducted.

\section{Findings}

\subsection{Perceptions of food security and insecurity}

Having enough bread (roti) to eat was considered across and within fieldwork sites as the most important test of food security. In rural as well as urban sites the availability of other foods was regarded as desirable, but at a lower priority than the availability of cereals or flour. Adequacy was thought of in several ways. The availability of a stock of grain or flour to last an annual cycle was considered to be an important goal, but one that was rarely achieved by the poorer families.

Another oft-mentioned statement with respect to adequacy was the ability to satisfy the hunger of children - or literally to 'fill the bellies of our children'. In this case too, the main criterion was access to grain or flour.

The experience of not having had enough bread to eat was considered a rare occurrence even among the poorest in the fieldwork sites. In fact, no interviewee admitted to having had to go hungry in recent memory. It is possible, of course, that respondents were embarrassed to reveal the extent of their deprivation. This, however, was not the case when people discussed their consumption of food items other than plain bread or roti.

It was common for poor informants across fieldwork sites to make do with very simple accompaniments to bread to complete their meals. The absence of an accompaniment was regarded as a deprivation, but not an insurmountable one. In the rural sites, as well as some urban ones, there was a great deal of exchange or charitable giving of accompaniments such as fresh milk, buttermilk (lassi), tea, sugar, chillies, and cooked vegetables. When asked about their first priority once they had enough bread, many informants said they could make do with uncooked chutney (made from chillies, salt or other freshly available produce), cooking oil, fresh milk, seasonal fruit, buttermilk, or tea. The preferred meal consisted of cooked vegetables or pulses, or even meat, though the latter was consumed by our informants on very rare occasions. The experience of having to eat simple bread with just water was far more familiar (or easily admitted) among the poorest than that of not having enough bread to eat. Reliance on a very simple and non-diversified diet of bread was not only common among the poor in the rural areas, but also among the urban poor in our fieldwork sites.

Perceptions regarding the time cycle of the availability of staples varied between individuals and families with different livelihood strategies and in various types of locations. For the poor in rural and peri-urban areas, but also for some of the poor in urban areas, the main source of security was their own private store of grain which might cover the annual cycle. There was a rare case of a casual labourer in the peri-urban area in Punjab for whom the timeline for food security was as short as a day. This family relied on daily wage labour in order to purchase enough flour for their meals. A number of other poor families in this area, and those in other urban areas, also relied on daily purchases of flour, but had longer time horizons in terms of security, as they either had greater cash buffers, or because they worked for weekly or monthly salaries.

\subsection{Grain acquisition strategies}

Growing sufficient grain and keeping it for selfconsumption - and selling the surplus in the market - was the dominant strategy of landowning families. They were able to store enough grain from the harvest to last them the entire year, and milled that grain according to need in small quantities. This same strategy was followed to a great extent, but with less security, by the landless and the landpoor. Those who worked as sharecroppers or tenants mimicked the behaviour of landowners. In the semi-arid site in Sindh, for example, sharecropping with 50 per cent shares in the harvest was still common. Typically, however, sharecropping could take care of only four to six months of grain requirements for a family. 
Since sharecropping tenancies were virtually extinct in our fieldwork villages, it was possible to observe the grain acquisition strategies of the landless poor who worked as casual labourers. For these families too, the main grain harvest (in most cases the wheat harvest in March-April) was the important time during the annual cycle for grain acquisition. The poor regularly relied on harvest labour to build up their stocks. The wage for harvest labour across the fieldwork sites was paid in terms of grain. The poor from the semiarid site in Punjab reported that harvest labour was available for 20-30 days during April. A realistic goal for households with several ablebodied adults was to acquire and store six to seven months' cereal requirements from harvest labour alone. For the rest it was understood that other sources of livelihood had to be deployed to purchase the next grain crop if available (usually rice), or to buy flour from local shops. Harvest labour was a common strategy even in the periurban site in southern Punjab.

Another related activity that was found in both Punjab and Sindh - particularly among families without able-bodied workers - was gleaning harvested fields for leftover grain. Some of the families who had engaged in this activity reported that they could gather up to three maunds (one maund is equal to $40 \mathrm{~kg}$ ) of grain in one season.

The circulation of grain was not restricted to rural areas alone. In urban Lahore a poor informant had received ten maunds of grain from her mother who lived in a rural area in 2010. She thought that this would last her seven months. Before this time she last received grain from the village in 2004. Also in Lahore a government employee had bought eight maunds of grain at harvest time from his native village. His family consumed this amount over a period of six months. Harvest time was an opportune moment for the acquisition of grain from family or the market - since it was plentiful and relatively cheaper compared with other times.

Those among the informants who relied on regular purchases of flour could be divided into two types. First there were families, including some in rural areas, who were neither engaged in agricultural self-employment, nor in harvest labour or related activities. These were among the poorest and relied exclusively on flour purchases from local shops out of their daily wages or begging and charity. For them the nonavailability of cash could pose a serious crisis though they could expect credit from their local shops on an exceptional basis. The other group were individuals and families who were relatively secure in the flow of cash incomes - or had some cash savings.

The basic condition for securing at least some months' worth of grain requirements was the availability of able-bodied workers within the family. This actually translated into the availability of male workers who could at least act as guardians of women and children working on other people's fields. In the absence of ablebodied workers or adult males, families were reduced to the valuable but far less remunerative gleaning activities. Beyond this, people relied on begging, charity, and borrowing, though for those in a weak economic condition the expectation of loans being returned were discounted by the lenders. Some of the market-based activity beyond the harvest stores was limited to the local circulation of grain. Local shops often held stocks of local grain which was sometimes sold not for cash but against the promise of a return of grain.

The poor in rural areas, but also in urban and peri-urban areas, appeared to rely on annual grain cycles in which their interaction with the market or flour prices was somewhat limited. Those among the poorest and most marginalised in the rural fieldwork sites who relied on daily flour purchases also happened to be the very individuals and families who were already in receipt of assistance, charity and borrowings. Price shocks in wheat or flour, therefore, were likely to have disproportionately affected the urban poor and non-poor who used the retail market for flour on a regular basis.

\subsection{Sources of shock}

Some conspicuous sources of economic shock, and those which might affect individual, family and community perceptions of food security, were common across fieldwork sites. Others differed according to context. For example, in the two non-irrigated villages the threat of drought was a common source of food insecurity. A drought in the semi-arid southern Punjab village some four years previously had led to the displacement of a large part of the population. In the Sindh semiarid village, migration cycles around rainfall were a common and accepted way of life. 
Interestingly, in the two irrigated sites, seasonal shortage of irrigation water was reported as a common source of shock. Both sites are on the tail of canals and so theft and misuse of water by landlords at the head of a canal is perceived as a threat by landlords as well as landless agricultural workers.

Price shocks were conspicuous in peri-urban and urban sites where there was much greater reliance on non-agricultural wage labour activities. Food price rises of the 2007-08 period left an imprint in these communities. Across the fieldwork sites, the period at the end of 2007 and the beginning of 2008 was remembered as a time of very high wheat prices and shortages of wheat and flour from the market. In the semi-arid village in Sindh this overall market effect was compounded by road and market closures due to large-scale rioting in the area following the assassination of former Prime Minister Benazir Bhutto in December 2007. In the urban and periurban sites in Punjab too, there were intermittent shortages and price spikes for a longer period starting at the end of 2007 and carrying on into 2008. Wheat and flour would disappear from the market, only to reappear at inflated prices. The most severe effect was felt in the semi-arid site in southern Punjab, which happens to be at a distance of some $40 \mathrm{~km}$ from the nearest market. In this village local shops ran out of the wheat stock towards the end of the crop cycle (February 2008), and residents had to travel to the market town at considerable expense to purchase wheat or flour.

There was an interesting contrast in perceptions of economic shock, depending on the precise circumstances of the interaction. In group discussions, informants were quick to mention food inflation in the period since 2007 as a major economic shock. In individual interactions, however, informants preferred to focus more specifically on their own personal stories of idiosyncratic shock.

The families that had been identified as being among the poorest in their respective communities were, in fact, those who had suffered serious idiosyncratic shocks in the shape of the loss of an adult family member, serious illness, or loss of property or livelihood. It was perhaps understandable that for these individuals and families even the very dramatic economic and price shocks paled in comparison in their effects with what they had or were going through. There were also idiosyncratic shocks that were not related to mortality or serious morbidity, but nevertheless overrode the effect of other shocks. Some of these were related to insecure wage and work conditions.

The main sources of shock experienced by informants in rural and urban fieldwork sites could be classified under four types:

(a) environmental shocks such as those relating to drought, or even irrigation water shortages in the more prosperous villages; (b) severe idiosyncratic shocks related to mortality and serious morbidity of family members; (c) idiosyncratic shocks related to the accidental loss of assets, or loss due to unequal and insecure contractual conditions; and (d) economic shocks transmitted through price volatility and inflation. For poor informants in the fieldwork sites, price volatility was a somewhat less significant source of uncertainty than either covariate environmental distress such as drought or flooding, or severe idiosyncratic shocks emanating from ill health, life cycle events, or poorly functioning insurance, credit and labour markets.

\subsection{Coping strategies}

Any discussion of the strategies that the poor in the fieldwork communities use to cope with adverse economic shocks must begin with the acknowledgement that the entire annual cycle of these communities is constructed around the mitigation of risk and the effects of the various shocks to which individuals and communities might be vulnerable. In the two semi-arid villages that are prone to drought-related crop failures, for example, seasonal migration and transhumance are self-conscious strategies on the part of the poor to diversify their means of sustenance.

The most serious shocks faced by our informants were those related to mortality or morbidity, particularly of family members of working ages. In the absence of sufficient family workers people are seen to downgrade their food acquisition strategy from harvest labour to gleaning, and then eventually to begging and charity. The existence of a layered labour market for harvest work allows such strategies to be adopted. At the same time the prevalent institutions of charity create the space in which 
activities like begging can be remunerative. Extreme cases of stress have led to asset sales among our informants. The sale of landed property, if held, marks the transition of a family into poverty and marginalisation. For most of the poor there is no land to sell in the first instance, and farm animals are used as stores of wealth.

Probes into the effects of price shocks revealed different effects across survey sites. Price shocks did have a strong impact among urban and periurban families, who reported adopting various strategies in order to cope with them. Some informants reported that they began to shop more carefully, and sought out bargains, or tried to obtain subsidised food and other benefits promised by the government. They also reduced their consumption of food items as well as items of clothing during this period. These findings are in line with econometric analysis of crosssectional and panel household data (Friedman $e t$ al. 2011), which shows reduced food consumption in urban households but a smaller impact in rural ones.

Government programmes had been in evidence in the various fieldwork sites in 2008 and subsequently. In some places there was a physical supply of subsidised flour and sugar at times of market shortage and price spirals. Some of this aid was distributed through local governments, while in other cases the provincial government is thought to have been the intervention agency. Distribution was on a first-come-first-served basis, with no lists or records used to order, rank or target beneficiaries. The presence of the various safety net interventions in five of the fieldwork sites was probed using community group interactions. The federal government's cash transfer programme was present in most of the survey sites.

\section{Conclusion}

The centrality of main staples, in effect wheat or wheat flour, in the food security perceptions of rural and urban households alike is in line with the policy focus on wheat availability. The acquisition and storage of the main staple for the annual cycle is a dominant livelihood strategy not only among farmers, but also among the rural landless, as well as in many households in peri-urban and urban areas. It can be argued that, rather than money, the main staple or grain is the primary numéraire in the welfare considerations of a large proportion of Pakistani households, whose economic choices are already geared towards reducing their exposure to price volatility. ${ }^{1}$

This supports the rationale for the food security strategy pursued by the government in the aftermath of the price crises of 2007-08, with its focus on ensuring the smooth functioning of markets and the prevention of supply shortages. Using procurement prices to bring domestic grain prices closer to world prices led to increases in output, thus benefiting the grain acquisition strategies of farm and labour households alike. Families without able-bodied adults may also benefit from higher local output and availability of grains through access to gleaning and charity. For families without direct access to grains, alignment with world market prices might, on balance, be protective if it would prevent unpredictable price spikes and shortages.

For the rural and urban poor alike, environmental as well as idiosyncratic events are more significant sources of adverse shock than price volatility. While a food security strategy that prevents price volatility and shortages deals with a politically conspicuous source of adverse economic shock, it does not, by itself, protect the vulnerable from other more debilitating shocks which can be independent of price shocks or might exacerbate them. Seasonality is another persistent constituent of food insecurity which is yet to attract the attention of food security strategy or social protection policy.

The primary focus of households as well as government on staple foods, or the prevention of hunger, implies that other food items, even relatively simple ones such as vegetables and spices are considered useful additions to the basic staple, but not always as essential. This is, obviously, a measure of the poverty of these families rather than an objective statement about food adequacy. The non-staple component of food consumption may allow for more nutritious choices than are currently salient, which a more nutrition-oriented food security policy ought to promote.

Coping strategies include cutting out non-staple items, reducing the food intake of some household members, migration, borrowing, begging, and women entering the workforce. In 
general, the annual life cycle of poor communities already seems to be organised around the mitigation of risk and uncertainty with respect to food security. External support takes a variety of forms including government programmes, private charities, shrines and

\section{Notes}

* This article is based on work done as part of a research study on the impact of food price inflation commissioned by the International Food Policy Research Institute (IFPRI) Delhi.

1 Incidentally, this finding calls into question some of the interpretations of econometric

\section{References}

Alderman, H. and Garcia, M. (1992) Food Security and Health Security: Explaining the Levels of Nutrition in Pakistan, Policy Research Working Paper Series 865, Washington DC: World Bank Chung, K.; Haddad, L.; Ramakrishna, J. and Riley, F. (1997) Alternative Approaches to Locating the Food Insecure: Qualitative and Quantitative Evidence from South India, Discussion Paper 22, Washington DC: Food Consumption and Nutrition Division, International Food Policy Research Institute

Coates, J.; Webb, P. and Houser, R. (2003) Measuring Food Insecurity: Going Beyond Indicators of Income and Anthropometry, Washington DC: Food and Nutrition Technical Assistance, Academy for Educational Development

FAO (1996) Report on the World Food Summit 1996, WFS 96/REP, Rome: Food and Agriculture Organization neighbourly help. There is preliminary evidence that the social safety net interventions are beginning to have wider outreach than ever before, and that these might be leveraged for greater food security and pro-nutrition outcomes.

analyses suggesting that households might be willing to reduce consumption and sell part of their grain store in response to higher prices (Friedman et al. 2011).

Friedman, J.; Hong, S.Y. and Hou, X. (2011) The Impact of the Food Price Crisis on Consumption and Caloric Availability in Pakistan: Evidence from Repeated Cross-sectional and Panel Data, Washington DC: Hunger, Nutrition and Population Discussion Paper, World Bank Gazdar, H. (2011) 'Social Protection in Pakistan: In the Midst of a Paradigm Shift', Economic and Political Weekly 46.28: 59-66

SDPI and WFP (2004) Food Security Analysis of Rural Pakistan 2003, 2004, Islamabad: World Food Programme-Sustainable Development Policy Institute joint publication SDPI, WFP and SDC (2009) Food Insecurity in Pakistan, Islamabad: Sustainable Development Policy Institute, World Food Programme and Swiss Development Cooperation 